\title{
Erratum to: Effect of cationic polymethacrylates on the rheology and flocculation of microfibrillated cellulose
}

\author{
Anni Karppinen - Arja-Helena Vesterinen - Tapio Saarinen • \\ Pirjo Pietikäinen · Jukka Seppälä
}

Published online: 4 October 2017

(C) The Author(s) 2017. This article is an open access publication

\section{Erratum to: Cellulose (2011) 18:1381-1390 DOI 10.1007/s10570-011-9597-9}

The article "Effect of cationic polymethacrylates on the rheology and flocculation of microfibrillated cellulose", written by Anni Karppinen, Arja-Helena Vesterinen, Tapio Saarinen, Pirjo Pietikäinen and Jukka Seppälä, was originally published Online First without open access. After publication in volume 18, issue 6, pages 1381-1390, the author decided to opt for Open Choice and to make the article an open-access publication. Therefore, the copyright of the article has been changed to (C) The Author(s) 2017, and the article is forthwith distributed under the terms of the Creative Commons Attribution 4.0 International License (http://creativecommons.org/licenses/by/4.0/), which permits use, duplication, adaptation, distribution and reproduction in any medium or format, as long as you give appropriate credit to the original author(s) and the source, provide a link to the Creative Commons license, and indicate if changes were made.

The online version of the original article can be found under doi:10.1007/s10570-011-9597-9.

A. Karppinen · A.-H. Vesterinen - T. Saarinen ·

P. Pietikäinen · J. Seppälä $(\square)$

School of Chemical Technology, Polymer Technology,

Aalto University, P.O. Box 16100, 00076 Aalto, Finland

e-mail: jukka.seppala@aalto.fi 